\title{
Lateralization of complex behaviours in wild greater flamingos
}

Annabelle Vidal ${ }^{\text {a }}$, Charlotte Perrot a, b, Jean-Nicolas Jasmin ${ }^{\mathrm{c}}$, Eva Lartigau a, Antoine Arnaud ${ }^{\mathrm{a}}$, Frank Cézilly ${ }^{\mathrm{d}}$, Arnaud Béchet a, * a Institut de recherche de la Tour du Valat, Le Sambuc, Arles, France b CEFE, CNRS, Université Montpellier, Université Paul-Valéry Montpellier 3, EPHE, IRD, Montpellier, France c INRA, UMR1083 Sciences pour l'œnologie, Montpellier, France d Université de Bourgogne-Franche Comté, Equipe Ecologie-Evolutive, UMR CNRS 6282 Biogéosciences, Dijon, How to cite :

Vidal A., Perrot C., Jasmin J.-N., Lartigau E., Arnaud A., Cézilly F., Béchet A. 2018. Lateralization of complex behaviours in wild greater flamingos. Animal Behaviour 144:67-74. doi: 10.1016/j.anbehav.2018.07.017

\begin{abstract}
Lateralization refers to the preferential use of one side of the body to perform certain tasks, often as a consequence of the specialization of cerebral hemispheres. Individuals may benefit from lateralization if it allows them to perform complex tasks simultaneously. Studies on laterality further suggest that sex and age can influence the extent of lateralization. However, most studies on lateralization have been performed on captive individuals, exposed to simplified environments and expressing limited behavioural repertoire. Here, we evaluated behavioural lateralization in the greater flamingo, Phoenicopterus roseus, through observations of wild individuals 5-37 years old. We examined the lateralization of simple behaviours (resting postures) and of several demanding behaviours requiring enhanced motor control and coordination (stamping for food and five courtship postures). Resting postures were not lateralized. In contrast, nearly all flamingos were completely lateralized for stamping, with a significant predominance of right-footed individuals. During courtship displays, twist-preens were significantly lateralized, yet with no dominant laterality at the population level. Finally, we detected a slight positive effect of age on the intensity of twistpreen lateralization, which may be related to the increased complexity of courtship displays with age in this species. Our results support the hypothesis that lateralization manifests in complex behaviours, even in wild animals.
\end{abstract}

Laterality refers to the preferential use of one side of the body to perform certain tasks (Rogers \& Andrew, 2002; Rogers, Vallortigara, \& Andrew, 2013). Almost ubiquitous in animals (reviewed in Frasnelli, Vallortigara, \& Rogers, 2012; Vallortigara \& Rogers, 2005), laterality results from the specialization of cerebral hemispheres for processing tasks, which has potential benefits in terms of survival and reproduction (Magat \& Brown, 2009; Rogers, Zucca, \& Vallortigara, 2004; Vallortigara \& Rogers, 2005). An advantage of lateralization for simultaneous task performance was reported by Rogers et al. (2004), who found that lateralized chickens, Gallus gallus domesticus, learned to discriminate between grains and gravel when exposed to a mock predator, whereas nonlateralized chickens did not. In general, lateralized individuals tend to perform better in demanding behaviours requiring higher cognitive skills (Dharmaretnam \& Rogers, 2005; Güntürkün et al., 2000; Vallortigara \& Regolin, 2006; Dadda \& Bisazza, 2006; review in Rogers et al., 2004) and weaker lateralization is manifested in easier* tasks (Fagot \& Vauclair, 1991; Roche, Binning, Strong, Davies, \& Jennions, 2013; Wells \& Millsopp, 2009). Moreover, the degree of lateralization can be limited by the cost of making suboptimal decisions when relevant information appears from both sides of the body (Dadda, Zandonà, Agrillo, \& Bisazza, 2009), or when a task must be performed symmetrically (e.g. scratching oneself). Lateralization is expressed at the individual level if each animal has its own laterality, and at the population level if a majority show the same laterality. Tasks that tend to be carried out solitarily are expected to generate individual level laterality (Vallortigara \& Rogers, 2005), whereas population level lateralization is often found in social tasks that require individuals to align their preference with the rest of the population, such as in fish schooling (Vallortigara \& Rogers, 2005). As a consequence, population level lateralization is predicted for social behaviours of gregarious species (Bisazza, Cantalupo, Capocchiano, \& Vallortigara, 2000; Ghirlanda \& Vallortigara, 2004; Vallortigara \& Rogers, 2005).

Individual characteristics may also influence the degree of lateralization. For instance, hand control improves slowly with age in primates, with older individuals being more strongly lateralized than younger ones for tool manipulation (Humle \& Matsuzawa, 2009; Teixeira, 2008; Ward, Milliken, Dodson, Stafford, \& Wallace, 1990). The degree of lateralization can also be sex dependent (Adret \& Rogers, 1989; Camp, Robinson, \& Becker, 1984; Romano et al., 2015; Sarasa, Soriguer, Serrano, Granados, \& Pérez, 2014), due to sexual or sex-specific selection which can result in differences in the regulation of brain ontogeny by steroid hormones between males and females (Pfannkuche, Bouma, \& Groothuis, 2009; Vallortigara \& Rogers, 2005). Finally, environmental factors including sensory and social experience influence asymmetrical development of the brain and, hence, may explain individual variation in lateralization (reviewed in Güntürkün \& Ocklenburg, 2017).

Despite an accumulation of laterality studies in vertebrates, predicting the strength of lateralization for specific behaviours remains difficult. There may be several reasons for this. First, one of the strongest explanatory variables for lateralization, 
task difficulty, is challenging to quantify a priori. Second, laterality of some behaviours may result from the asymmetry of brain development for other benefits it may procure (Rogers, 2009). A third possible issue is that studies are most often carried out in artificial environments that may alter behaviour compared to natural environments, where stimuli coming simultaneously from many directions can hinder the development of lateralized responses (Krakauer et al., 2016; Rogers \& Andrew, 2002; Vallortigara \& Rogers, 2005; Ventolini et al., 2005). Hence, studying the extent of laterality in situ is more likely to reveal the extent of lateralization in the environment in which it evolved.

In this context, we investigated the extent of behavioural lateralization in a wild population of greater flamingos, Phoenicopterus roseus. Through repeated observations of ringed flamingos of known age and sex and of unringed individuals, we examined laterality during resting, a simple behaviour, and during foraging and courtship displays, two more demanding behaviours in terms of motor coordination and cognitive skills (Johnson \& Cézilly, 2007). Indeed, communal courtship displays imply the processing of multiple tasks simultaneously (Johnson \& Cézilly, 2007; Perrot et al., 2016), such that lateralization of displays is expected. Finally, we evaluated the effect of age and sex on the extent of lateralization among individuals.

\section{METHODS}

\section{Species and Study Site}

The greater flamingo is a long-lived colonial species with a seasonal monogamous mating system (Cézilly \& Johnson, 1995; Johnson \& Cézilly, 2007; Perrot et al., 2016). Observations were made in the Camargue (southern France), one of the most important breeding sites of the greater flamingo in the Mediterranean region (Johnson \& Cézilly, 2007). Since 1977, on average $12 \%$ (range 7-30\%) of the chicks fledged in the Camargue have been marked each year with both a metal ring on the left leg and a PVC plastic ring engraved with a unique three- or four-digit alphanumerical code on the right leg. Sex of the individuals was determined either from molecular data (Balkiz et al., 2007) or from repeated sex assignment from observations based on sexual dimorphism (males being generally larger than females) and behaviour.

Observations of both ringed and unringed adults were made at several saltpans and marshes from January to April in 2011, 2014 and 2015.

\section{Resting Behaviour Observations}

Flamingos usually rest with the head lying along their back and the neck curved, making a loop towards one side of the body (Johnson \& Cézilly, 2007). In this position, sleeping individuals can remain vigilant and monitor the environment through regular eye opening. We recorded the side position of the neck in resting ringed individuals (neck position) using scan sampling (Altmann, 1974). We considered the neck to be on the right side when it was curved to the right of the flamingo's sagittal plane (and conversely for the left side; Anderson, Williams, \& O'Brien, 2009).

Flamingos also rest on one leg, which has been shown to minimize energy demand compared to standing on both legs (Chang \& Ting, 2017). We noted on which leg (right or left) the observed individual stood on during resting (leg resting). Left standing could be missed more often than right standing during scan sampling because PVC rings (on the right leg) are easier to read than metal rings (on the left leg), and this could generate false right lateralization. Hence, we only retained observations for which both metal and plastic rings had been read. Observations of each ringed individual were made on different days. Only data from resting individuals observed on at least three occasions were retained for analysis.

\section{Foraging Behaviour Observations}

Among the different foraging techniques used by flamingos, stamping could be lateralized. When stamping, flamingos immerse their bill and circle (clockwise or anticlockwise) around it while stamping the soil to resuspend invertebrates from the mud (Johnson \& Cézilly, 2007). When turning clockwise, flamingos use their left leg to make the first step forwards, while their right leg holds the weight of their body to ensure balance (and conversely for anticlockwise stamping).

Individuals foraging by stamping were observed using focal sampling with binoculars or a telescope (Alt mann,1974). We scored the direction of rotation in at least three bouts per individual. A bout started with a series of rotations (more than two) in the same direction, and stopped when the individual changed direction, or when the individual walked to ano ther patch before stamping again. We retained focal bouts that lasted for at least $5 \mathrm{~min}$. As only four ringed individuals were observed stamping, we recorded most data on unringed individuals over six sites visited up to three times. We waited 1 week before resampling at the same site to minimize the risk of resampling the same individuals.

\section{Courtship Display Observations}

During winter, male and female greater flamingos perform courtship displays in groups of a few to several hundreds of males and females (Johnson \& Cézilly, 2007, Perrot et al., 2016). We recorded 5 min videos of ringed flamingos during courtship. 
We then analysed sequences of courtship postures of focal individuals (Fig. 1, Table 1; Altmann, 1974) and recorded the side on which asymmetrical postures were performed. Following Tomkins, Thomson, and McGreevy (2010), we defined laterality for the walk display as the side of the first step initiating a walking bout. Similarly, laterality for head-flag and twist-preen (or preens) corresponds to the side of the first head-flag or twist-preen of a bout (Appendix 1). Only data from displaying individuals that had at least three repetitions of asymmetrical postures were retained. When a courtship behaviour was found to be lateralized, we checked that the lateralization resulted from an individual preference rather than from behavioural contagion (Zentall, 2001) during courtship (see Appendix 2).

\section{Ethical Note}

Ringing of greater flamingo chicks in France was authorized through a personal permit (number 405) issued to Alan Johnson and Arnaud Béchet by the Centre de Recherche sur la Biologie des Populations d'Oiseaux (CRBPO, Muséum national d'histoire naturelle, France). The study protocol was reviewed and approved by the CRBPO. To catch the chicks, the entire crèche is slowly pushed into a large enclosure by many people. Chicks are released immediately after ringing. The entire operation lasts less than 3 $\mathrm{h}$. The data collected here are resightings made from large distances using a telescope so as not to disturb the flamingos.

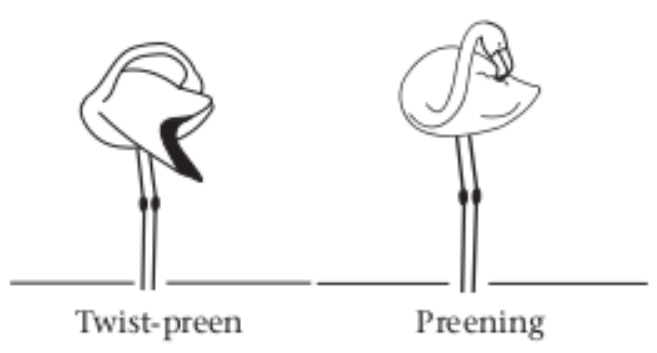

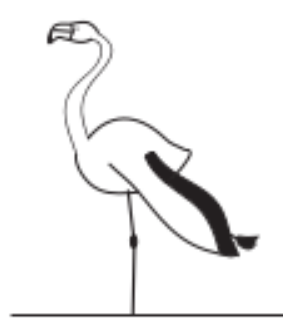

Wing-leg stretch

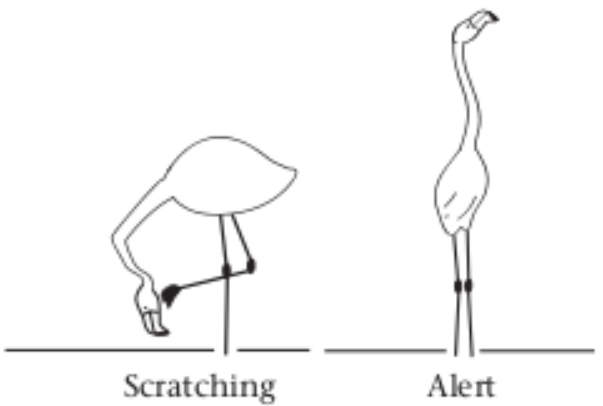

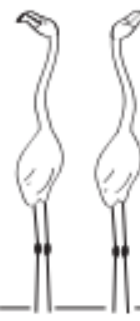

Head flagging

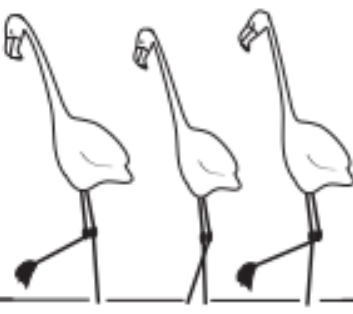

Walk

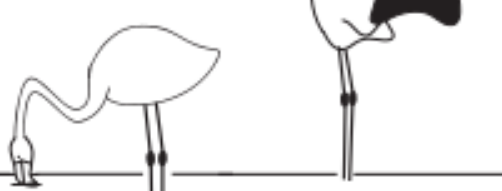

False feeding

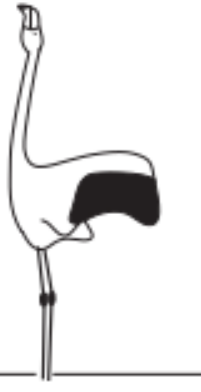

Wing-salute

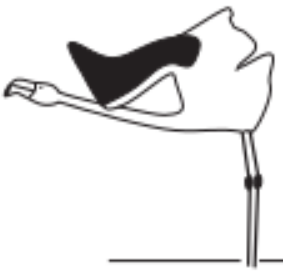

Inverted wing-salute

Figure 1 Graphical representation of greater flamingo postures used in sequences of communal courtship displays (also see Table 1 for a complete description).

\section{Statistical Analysis}

\section{Individual level lateralization analysis}

For each individual and behaviour, we calculated an index of laterality intensity, $\mathrm{L}$ as $\mathrm{L}=1 \mathrm{k} / \mathrm{n}-0.51$ where $\mathrm{k}$ is the number of right-side behaviours among $\mathrm{n}$ individual observations (Jasmin \& Devaux, 2015). This index increases statistical power to detect lateralization through pooling together left- and right-lateralized individuals. To assess whether a behaviour was on average significantly lateralized, we compared the mean $\mathrm{L}$ of the observed population to the confidence intervals of population means generated from simulations of a population of ambidextrous individuals with the same sampling intensity as the observed population (same number of individuals and observations per individual). Each simulation gave a number of right-side behaviours from a binomial distribution with $\mathrm{P}=0.5$ for each individual. We then calculated the mean $\mathrm{L}$ for each of 10000 simulated such populations and used these population means to obtain 95\% confidence intervals for an ambidextrous population with the same sample size as the observed population. Matching the observed sampling effort is crucial because L varies with the number of repeated measurements, even for ambidextrous individuals (Jasmin \& Devaux, 2015). If the observed L mean was outside the confidence intervals for distributions obtained through simulations, we concluded that the observed individuals were lateralized for that behaviour. This approach alleviates the limits of parameter fitting with few observations per individual. 


\section{Population level lateralization analysis}

When a behaviour was found to be lateralized, we evaluated whether there was a preferred side used for this behaviour at the population level by using a chi-square test to test whether the proportion of right- and left-acting individuals differed from 0.5.

\section{Sex and age effects on behavioural lateralization}

The expected value of $\mathrm{L}$ deviates from zero for ambidextrous individuals even when they are observed relatively frequently (Jasmin \& Devaux, 2015). For instance, $\mathrm{L}=0.19,0.12$ and 0.088 for ambidextrous individuals with, respectively, $\mathrm{n}=5,10$ and 20 observations. Consequently, we corrected $\mathrm{L}$ for the number of repeated observations $\mathrm{n}$ by calculating the expected mean intensity of lateralization of ambidextrous flamingos with a given $n$ (Jasmin \& Devaux,2015):

$$
\overline{L_{n}}=\sum_{k=0}^{n} \frac{n !}{k !(n-k) !} 0.5^{n}\left|\frac{k}{n}-0.5\right|
$$

We then calculated the corrected laterality intensity index $\mathrm{L}_{\mathrm{c}}$ as the difference between the observed intensity of lateralization and the expectation under ambidexterity: $\mathrm{L}_{\mathrm{c}}=\mathrm{L}-\mathrm{L}_{\mathrm{n}}$.

To evaluate the effect of sex on individual lateralization we used Wilcoxon rank tests, and we performed a Theil—Sen regression to test for the age effect (this nonparametric estimator addresses heteroscedasticity and is robust to outliers, Sen, 1968). These effects were tested for behaviours recorded on ringed individuals for which we knew both age and sex (i.e. not for stamping behaviour) and for behaviours that were lateralized.

All analyses were conducted using the R programming language, version 3.03 (R Development Core Team, 2014).

\begin{tabular}{|c|c|c|}
\hline & Description & Video URL \\
\hline \multicolumn{3}{|c|}{ Asymmetrical behaviours } \\
\hline Twist-preen & $\begin{array}{l}\text { In a sudden movement, the bird twists its head and neck back on one side, drops down the } \\
\text { wing on the same side and appears to preen behind the wing. An individual may repeat this } \\
\text { movement rapidly while switching sides. This posture is often performed simultaneously by } \\
\text { several individuals }\end{array}$ & $\begin{array}{l}\text { vimeo_com } / 243858889 \text { (twist-preen alone) } \\
\text { vimeo_com } / 243857197 \text { (with wing-salute) } \\
\text { vimeo_com } / 244178066 \text { (with wing-salute } \\
\text { and imverted wing-salute) }\end{array}$ \\
\hline Preening & $\begin{array}{l}\text { The bird twists its head and preens one body side with its bill. An individual may repeat this } \\
\text { movement while changing sides. This behaviour is often followed by false feeding and can be } \\
\text { performed simultaneously by several individuals }\end{array}$ & vimeo.com $/ 250795231$ \\
\hline Wing-leg stretch & $\begin{array}{l}\text { The bird stretches a wing and a leg from the same body side for } 1-2 \mathrm{~s} \text {, much as during comfort } \\
\text { movement. This movement can be performed simultaneously by several individuals }\end{array}$ & vimeo.com $/ 250810717$ \\
\hline Scratching & $\begin{array}{l}\text { In a lowered position, the bird scratches its neck behind the chin using one of its legs. This } \\
\text { movement can be performed simultaneously by several individuals }\end{array}$ & vimeo.com $/ 250800090$ \\
\hline Alert & $\begin{array}{l}\text { The bird stands erect with its neck stretched upwards, the bill held high with the distal half } \\
\text { nearly horizontal }\end{array}$ & vimeo.com $/ 250793497$ \\
\hline Head flagging & $\begin{array}{l}\text { With its neck stretched, the bird flags its head jerkily from side to side. This movement is often } \\
\text { preceded by an alert posture }\end{array}$ & vimeo.com $/ 250791388$ \\
\hline Walk & The bird walks, sometimes simultaneously head flagging & vimeo.com/250792946 \\
\hline \multicolumn{3}{|c|}{ Symmetrical behaviours } \\
\hline False feeding & The bird dips its beak in water before taking it out immediately & vimeo.com/252330513 (with preening) \\
\hline Wing-salute & $\begin{array}{l}\text { In a sudden movement, the bird throws open its wings to their full extent, keeping its neck } \\
\text { stretched with its bill slightly above the horizon. This movement is often performed by several } \\
\text { individuals at the same time in the group display and usually precedes a twist-preen sequence }\end{array}$ & vimeo.com $/ 243857197$ (with twist-preen) \\
\hline Imverted wing-salute & $\begin{array}{l}\text { With its wings partially open, the bird bends forward from an erect position, so its tail is held } \\
\text { higher than its chest. The neck is extended forwards and in line with the body. Usually, this } \\
\text { movement is performed between two twist-preens }\end{array}$ & $\begin{array}{l}\text { vimeo.com/244178066 (with twist-preen } \\
\text { and wing- salute) }\end{array}$ \\
\hline
\end{tabular}

Based on Johnson and Cézilly (2007).

Tableau 1 Greater flamingo courtship behaviour definitions and hyperlink to video captures showing each posture

\section{RESULTS}

We recorded the neck position of 97 ringed individuals when resting ( 26 females, 43 males and 28 of unknown sex, with $3 \mathrm{e} 12$ observations per individual). Of these individuals, 91 were observed standing on one leg ( 25 females, 42 males and 24 of unknown sex, with $3 \mathrm{e} 10$ observations per individual). Rotation direction during stamping was recorded for 77 unringed individuals, with $3 \mathrm{e} 8$ bouts per individual. Finally, 80 ringed individuals were recorded performing courtship displays, including 40 females aged $8 \mathrm{e} 37$ years and 40 males aged $5 \mathrm{e} 34$ years. Number of observations per individual was $3 \mathrm{e} 15$ for alert, head-flag and preen, $3 \mathrm{e} 6$ for twist-preen and 3e9 for walk. The occurrence rate of all other components of courtship displays was too low to allow statistical analysis. 


\section{Individual and Population Level Lateralization}

Mean laterality index of neck position and leg-resting postures during resting and of walk, preening, alert and head-flagging courtship postures were similar to those of ambidextrous simulated populations (Fig. 2a, b, e, f, g), suggesting that these six postures were not lateralized. On the other hand, stamping, a complex foraging technique, and twist-preen, a courtship posture, were significantly lateralized (Fig. $2 \mathrm{c}$ and d). Since we performed a total of eight statistical tests for lateralization (Fig. 2), we used a Bonferroni-corrected threshold value of $\mathrm{a}=0.05 / 8=0.00625$ when evaluating $\mathrm{P}$ values for statistical significance. Stamping was strongly lateralized, as the observed $\mathrm{L}$ value was 16.4 standard deviations higher than the $\mathrm{L}$ expected under ambidexterity (P < 0.0001; Fig. 2c). During stamping, 63.6\% (49 of 77) of individuals turned only anticlockwise. Anticlockwise turns imply making the first step forwards with the right leg, while the left leg supports the body. Hence, the population was significantly right footed when stamping $\left(x^{2} 1=6.28, P=0.012\right)$. The remaining 28 individuals consistently turned clockwise in all observations, except for a single individual that turned both ways.

The probability of the observed mean $\mathrm{L}$ for twist-preen occurring in the simulated ambidextrous populations was 0.004 , which is statistically significant with a $=0.00625$ (Fig. 2d). However, in contrast to stamping, lateralization was weak and not significantly lateralized at the population level. Most individuals (14 of 20) initiated twist-preens at least once on both sides. About half the birds (12 of 20; no different from $\mathrm{P}=0.5, \mathrm{x}^{2} 1=0.45, \mathrm{P}=0.50$ ) initiated twist-preen sequences more often towards the left side (none significantly so even without correcting for the multiple test).

One behaviour, walk, had a P value of 0.035 in our simulations (Fig. $2 \mathrm{~h}$ ), which is significantly lateralized with a $=0.05$ but not with $\mathrm{a}=0.00625$. As the mean lateralization $\mathrm{L}$ for walk was only 0.24 , even if it had been statistically different from ambidexterity, the difference might not be biologically meaningful. Most individuals ( 35 of 45) initiated walking bouts with both legs and there was no population level lateralization for walk $\left(\mathrm{x}^{2} 1=0.08, \mathrm{P}=0.76\right)$. The laterality index $\mathrm{L}$ for walk and twist-preen of the 13 individuals that had both postures recorded were positively but not significantly correlated (Spearman rank correlation: $\mathrm{rS}=0.47, \mathrm{P}=0.10$ ). We included walk in the following analyses as if it were lateralized to test whether the population might be heterogeneous for the lateralization of that behaviour.

\section{Sex and Age Effects on Lateralization}

The corrected lateralization intensity $\left(\mathrm{L}_{\mathrm{c}}\right)$ of twist-preen did not differ significantly between the sexes (Wilcoxon rank test: $\mathrm{W}=31, \mathrm{P}=$ 0.26 ). The corrected lateralization intensity for twist-preen slightly but significantly increased with age (Theil-Sen estimator: slope $=$ $0.0097, P=0.00006, R^{2}=0.20$; removing a 37-year-old female with strong leverage decreased the $P$ value to 0.008 ; Fig. $3 a$ ). Finally, neither sex $(\mathrm{W}=214.5, \mathrm{P}=0.38)$ nor age (TheileSen estimator: $\mathrm{P}=0.86$; Fig. 3b) significantly explained individual variation for the corrected lateralization intensity of the walk display. Consequently, it appears that individuals are only slightly (if at all) lateralized for this display.

\section{DISCUSSION}

We found that wild greater flamingos exhibit nearly complete lateralization when foraging by stamping (with a small albeit statistically significant predominance of right-footed laterality at the population level) and weak lateralization for a sophisticated courtship posture which is most often part of multimovement sequences (twist-preen). No such lateralization was found at the individual or population level for less demanding leg- and neckresting postures.

Neck position during resting was found to be lateralized at the individual and population levels in captive Caribbean flamingos, Phoenicopterus ruber (Anderson et al., 2009) and lesser flamingos, Phoeniconaias minor (Anderson, 2009). Yet these results must be taken with caution because they probably resulted from small sample sizes, as shown by a similar study with much larger samples (Hughes, Cauthen, \& Driscoll, 2014). As shown by Hughes et al. (2014) and more formally by Jasmin and Devaux (2015), because laterality observations for a given individual are sampled from an underlying binomial distribution, deviation from left-right equality can occur by chance alone, even for ambidextrous individuals, and especially when few observations are made for each animal. Simulations of ambidextrous populations thus provide a robust approach to test for lateralization.

Several functional hypotheses can explain neck-resting ambidexterity. Wild flamingos may need to monitor conspecifics and predators from both sides of their body by alternating the side on which their neck rests. Or else, changing neck position may avoid muscular fatigue. Leg-resting ambidexterity may be explained by individuals alternately exposing each leg to the air to maintain a stable body temperature (Anderson \& Williams, 2010; Bouchard \& Anderson, 2011). 

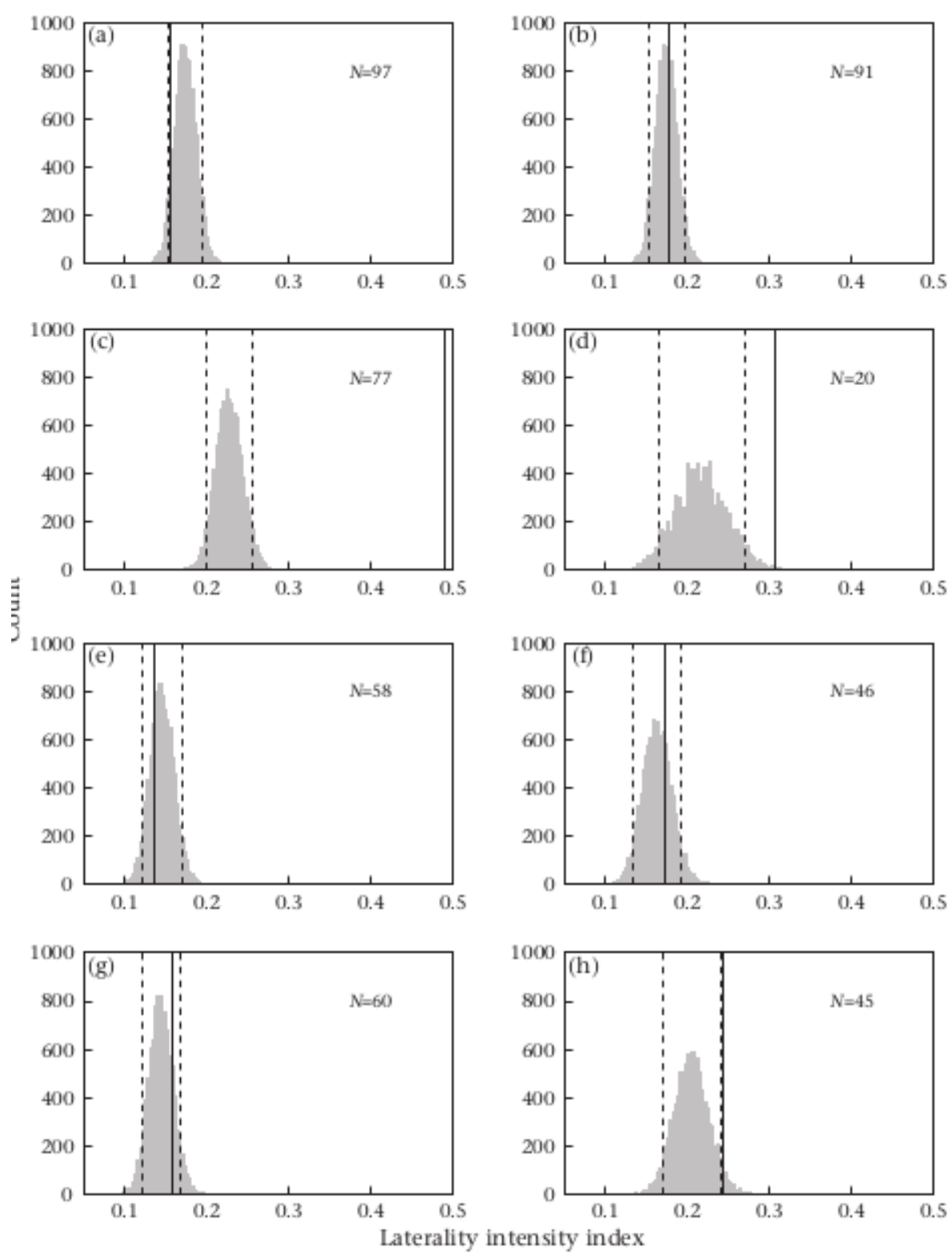

Figure 2 Frequency distribution of mean lateralization index $\mathrm{L}$ for 10000 simulated populations of ambidextrous greater flamingos with identical sampling effort as observations of (a) neck position, (b) leg-supporting posture, (c) stamping, (d) twist-preen, (e) preen, (f) alert, (g) head-flag and (h) walk. Solid lines represent the observed mean $L$ and dashed lines represent lower and upper limits of the simulated distributions for a $95 \%$ confidence interval. In (c) the mean $\mathrm{L}$ (solid line) is at 0.498 on the right hand-side.

Peluso and Anderson (2014) did not find evidence of lateralization of stamping in a zoo population of Caribbean flamingos. This discrepancy with our study results partly from our much larger sample size (number of individuals: $\mathrm{N}=77$; number of repeated observations per individual, $\mathrm{n}=3-8$; Peluso \& Anderson, 2014: $\mathrm{N}=14 ; \mathrm{n}=1-7$ ), and mainly from the ambidexterity of their animals (nine of their 14 animals rotated both clockwise and anticlockwise during stamping, whereas only one of our 77 animals did not systematically rotate in one direction). Another difference is that Peluso and Anderson (2014) tracked individuals over several days whereas we recorded each individual on a single day. It thus remains possible that our flamingos are ambidextrous for stamping over many days.

We also found stamping to be lateralized at the population level, as individuals preferentially used their right leg to make the first step when turning, whereupon the left leg held the weight of the body and thus ensured its balance. Population level lateralization during stamping may result from constraints imposed by surrounding conspecifics (Vallortigara \& Rogers, 2005). Circling in the same direction as neighbours could facilitate the action of vertical vortices that stir up food from the bottom. It may also avoid collisions among birds, as suggested for dense groups of red phalaropes, Phalaropus fulicarius, performing a circular feeding technique on water (Cooch, 1965). 


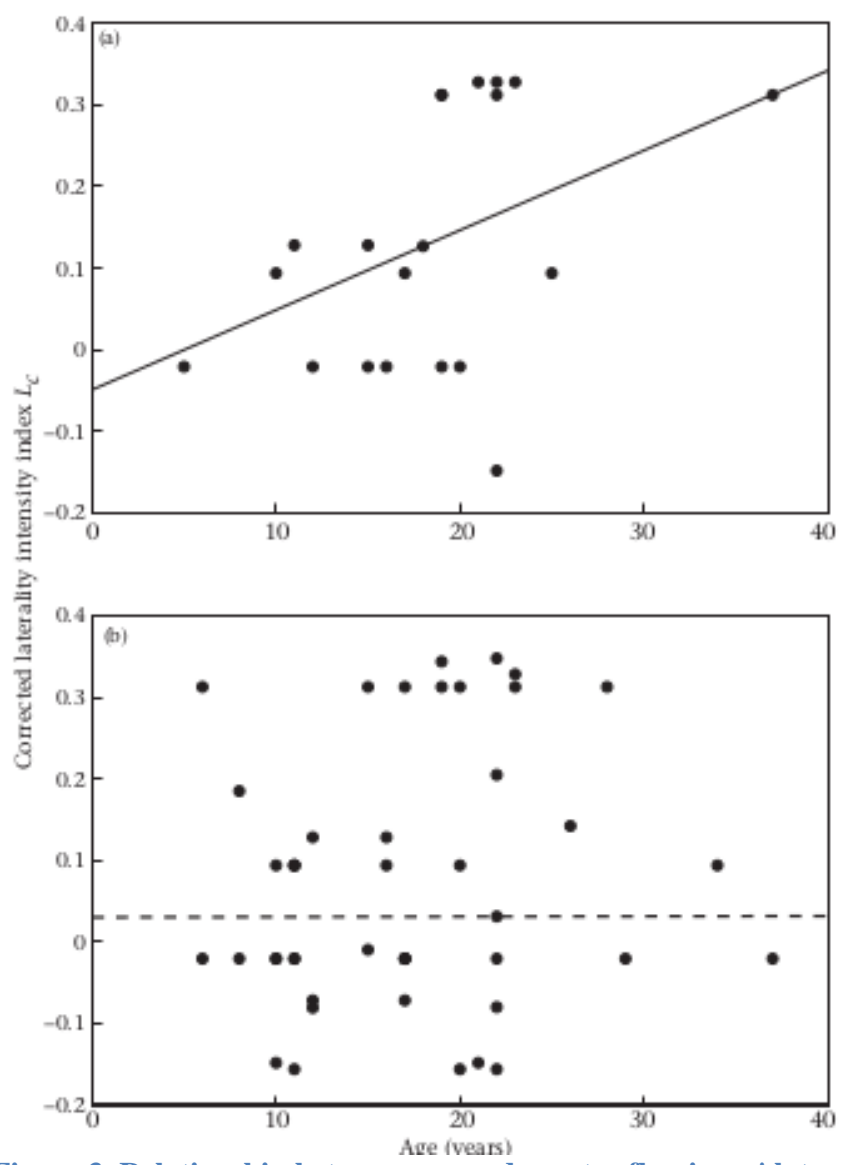

Figure 3. Relationship between age and greater flamingos' laterality index Lc for (a) twist-preen courtship behaviour (note that removing the 37-year-old individual did not change the statistical significance of the relationship) and (b) walk courtship behaviour.

A third plausible explanation is that this population level lateralization reflects the specialization of the right limbs (left hemisphere) for feeding tasks, a phylogenetically widespread pattern (Brown \& Magat, 2011; Harris, 1989; Rogers, 1980, 2009; Str€ockens, Güntürkün, \& Ocklenburg, 2013; Tommasi, 1999).

We expected walking during courtship to be significantly lateralized because it implies both movement and monitoring of conspecifics. However, conspecifics can be present on either (or both) side of the focal bird, thus forcing ambidexterity (Dadda et al., 2009). Similarly, alert, head-flag and preen postures may be performed on either side because of bilateral monitoring. If so, these postures could be a derived activity with current functions that still relate to the original functions of vigilance (alert and headflag) or preening (Bradbury \& Vehrencamp,1998; Tinbergen, 1952).

Our results support the hypothesis that twist-preen lateralization results from individual preferences rather than behavioural contagion (see Appendix 2). A possible explanation for the fact that twist-preen was the only lateralized courtship posture is that it is part of a stereotyped sequence of behaviours in which twist-preen rapidly follows one of three other behaviours (wing-salute, with probability of transition to twist-preen $\mathrm{P}=1$, inverted wing-salute with $\mathrm{P}=0.97$ and wing-leg stretch with $\mathrm{P}$ $=0.81$; Perrot, 2016). Lateralization of twist-preen may help achieve this rapid two-step sequence by limiting the complexity of this dance. This hypothesis predicts that the other behaviours of the sequence are lateralized; however, wing-salute and inverted wing-salute were symmetrical (making the prediction moot), and we gathered too few wing-leg stretch observations to assess its lateralization (seven birds were observed once or twice for that behaviour). In contrast, preen generally comes as a decelerating movement after long sequences of either head flagging (probability of transition from head flagging to preening, $\mathrm{P}=0.79)$, walking $(\mathrm{P}=0.75)$ or false feeding $(\mathrm{P}=0.52$; Perrot, 2016).

The behaviours we found to be lateralized imply strong motor coordination, whereas flamingos were ambidextrous for apparently simpler behaviours. Stamping implies leg movements and tongue pumping and filtering for foraging. Twist preening implies monitoring and coordinating with courtships by conspecifics. Thus lateralization of the most sophisticated behaviours we studied 
(stamping and twist-preen) may be explained by their complexity compared to simpler and less cognitively demanding resting behaviours (Vallortigara \& Regolin, 2006).

We expected twist-preen to be left lateralized (right-hemisphere control) at the population level as often observed for sexual and other social behaviours (Rogers, 2009, 2012). However, we failed to find evidence for this, in part because of the small size of our samples (20 individuals with 3-6 observations each) which nevertheless indicate that most birds do twist-preens on both sides. Again, the need to monitor conspecifics surrounding focal birds might override any neuronal asymmetries involved in twist preening.

We found a small positive effect of age on individual lateralization for twist-preen. Similarly, lateralization of foot scratching increases with age in captive Caribbean flamingos (Peluso \& Anderson, 2014), and lateralization is often stronger in older mammals (Canning et al., 2011; McGreevy \& Thomson, 2006). A possible explanation for positive relationships between age and lateralization is that performing complex behaviours is demanding and requires physiological maturation including the progressive lateralization of the brain. In flamingos, it has been shown that display complexity increases with age up to 20 years old (Perrot et al., 2016), a factor that may explain the concomitant lateralization of courtship postures such as twist-preen. Alternatively, lateralized individuals might increase in frequency as each cohort ages, perhaps because they enjoy better foraging success (Güntürkün et al., 2000) and higher survival (however, this would raise the question of why natural selection has not optimized lateralization early in development).

As expected, males and females had similar laterality which may result from relatively weak sexual dimorphism (Johnson \& Cézilly, 2007) and similar reproductive effort (Rendôn, Garrido, RendônMartos, Ramírez, \& Amat, 2014). Furthermore, flamingos' mutual mate choice and courtship displays differ only very slightly between male and female flamingos (Perrot, 2016). We found that, in wild greater flamingos, behaviours such as complex foraging techniques and sophisticated courtship displays are lateralized, whereas simpler behaviours such as resting are not. Our observations of neck side position during resting contrast with previous observations in captive flamingo populations (Anderson, 2009; Anderson et al., 2009) highlighting the importance of carrying out behavioural studies in the wild and of having sufficiently large sample sizes when modelling variables that follow a binomial distribution. Further investigations should examine the consequences of observed lateralization for individual performance and fitness in the wild, to understand the evolution of laterality.

\section{Acknowledgments}

This study was made possible by the long-term study on greater flamingos of the Camargue initiated by Luc Hoffmann and Alan R. Johnson and funded by Fondation Tour du Valat and Fondation MAVA. We are grateful to the many assistants who participated in the fieldwork over many years and all the people who helped in the ringing operations. We thank the ornithological park of Pont de Gau and the company Salins du Midi for the authorization to access their marshes without which this work would not have been possible. We are very grateful to Samuel Hilaire for the drawings of greater flamingo courtship postures. The paper received useful comments from Céline Devaux (Université de Montpellier) that contributed to considerably improving the final version of the manuscript.

\section{References}

Adret, P., \& Rogers, L. J. (1989). Sex difference in the visual projections of young chicks: A quantitative study of the thalamofugal pathway. Brain Research, 478, 59-73. https://doi.org/10.1016/0006-8993(89)91477-7.

Altmann, J. (1974). Observational study of behavior: Sampling methods. Behaviour, 49, 227-266.

https://doi.org/10.1163/156853974X00534.

Anderson, M. J. (2009). Lateral neck-resting preferences in the lesser flamingo (Phoeniconaias minor). Flamingo, Bulletin of the IUCNSSC/Wetlands International Flamingo Specialist Group, 17, 37-39.

Anderson, M. J., \& Williams, S. A. (2010). Why do flamingos stand on one leg? Zoo Biology, 29, 365-374.

Anderson, M. J., Williams, S. A., \& O'Brien, E. H. (2009). Individual differences in the preferred neck-resting position of Caribbean flamingos (Phoenicopterus ruber). Laterality: Asymmetries of body, Brain and Cognition, 14, 66-78. https://doi.org/ 10.1080/13576500802233722.

Balkız, Ô., Dano, S., Barbraud, C., Tekin, S., Ozesmi, U., Dundar, M., et al. (2007). Sexing Greater Flamingo chicks from feather bulb DNA. Waterbirds, 30, 450-453.

Bisazza, A., Cantalupo, C., Capocchiano, M., \& Vallortigara, G. (2000). Population lateralisation and social behaviour: A study with 16 species of fish. Laterality, 5, 269-284. https://doi.org/10.1080/713754381.

Bouchard, L. C., \& Anderson, M. J. (2011). Caribbean flamingo resting behavior and the influence of weather variables. Journal of Ornithology, 152, 307-312. https:// doi.org/10.1007/s10336-010-0586-9.

Bradbury, J. W., \& Vehrencamp, S. L. (1998). Principles of animal communication. Sunderland, MA: Sinauer. 
Brown, C., \& Magat, M. (2011). Cerebral lateralization determines hand preferences in Australian parrots. Biology Letters, 7 , 496-498. https://doi.org/10.1098/ rsbl.2010.1121.

Camp, D. M., Robinson, T. E., \& Becker, J. B. (1984). Sex differences in the effects of early experience on the development of behavioral and brain asymmetries in rats. Physiology \& Behavior, 33, 433-439. https://doi.org/10.1016/0031-9384(84) 90166-5. Canning, C., Crain, D., Eaton, T. S., Nuessly, K., Friedlaender, A., Hurst, T., et al. (2011). Population-level lateralized feeding behaviour in North Atlantic humpback whales, Megaptera novaeangliae. Animal Behaviour, 82, 901-909. https://doi.org/

10.1016/j.anbehav.2011.07.031.

Cézilly, F., \& Johnson, A. R. (1995). Re-mating between and within breeding seasons in the greater flamingo Phoenicopterus ruber roseus. Ibis, 137, 543-546.

Chang, Y.-H., \& Ting, L. H. (2017). Mechanical evidence that flamingos can support their body on one leg with little active muscular force. Biology Letters, 13, 20160948. https://doi.org/10.1098/rsbl.2016.0948.

Cooch, F. G. (1965). An example of sinistralism in Red phalaropes (Phalaropus fulicarius). The Auk: Ornithological Advances, 82, 276-277.

Dadda, M., \& Bisazza, A. (2006). Does brain asymmetry allow efficient performance of simultaneous tasks? Animal Behaviour, 72, 523-529.

Dadda, M., Zandonà, E., Agrillo, C., \& Bisazza, A. (2009). The costs of hemispheric specialization in a fish. Proceedings of the Royal Society of London B: Biological Sciences, 276, 4399-4407. https://doi.org/10.1098/rspb.2009.1406.

Dharmaretnam, M., \& Rogers, L. J. (2005). Hemispheric specialization and dual processing in strongly versus weakly lateralized chicks. Behavioural Brain Research, 162, 62-70. https://doi.org/10.1016/j.bbr.2005.03.012.

Fagot, J., \& Vauclair, J. (1991). Manual laterality in nonhuman primates: A distinction between handedness and manual specialization. Psychological Bulletin, 109, 76-89. https://doi.org/10.1037/0033-2909.109.1.76.

Frasnelli, E., Vallortigara, G., \& Rogers, L. J. (2012). Left-right asymmetries of behaviour and nervous system in invertebrates.

Neuroscience \& Biobehavioral Reviews, 36, 1273-1291. https://doi.org/10.1016/j.neubiorev.2012.02.006.

Ghirlanda, S., \& Vallortigara, G. (2004). The evolution of brain lateralization: A game-theoretical analysis of population structure. Proceedings of the Royal Society B: Biological Sciences, 271, 853.

Güntürkün, O., Diekamp, B., Manns, M., Nottelmann, F., Prior, H., Schwarz, A., et al. (2000). Asymmetry pays: Visual lateralization improves discrimination success in pigeons. Current Biology, 10, 1079-1081.

Güntürkün, O., \& Ocklenburg, S. (2017). Ontogenesis of lateralization. Neuron, 94, 249-263.

https://doi.org/10.1016/j.neuron.2017.02.045.

Harris, L. J. (1989). Footedness in parrots: Three centuries of research, theory, and mere surmise. Canadian Journal of Psychology, 43, 369-396. https://doi.org/ 10.1037/h0084228.

Hughes, A. L., Cauthen, J., \& Driscoll, C. (2014). Testing for behavioral lateralization in observational data: A Monte Carlo approach applied to neck-looping in American flamingos. The Wilson Journal of Ornithology, 126, 345-352. https:// doi.org/10.1676/13-122.1.

Humle, T., \& Matsuzawa, T. (2009). Laterality in hand use across four tool-use behaviors among the wild chimpanzees of Bossou, Guinea, West Africa. American Journal of Primatology, 71, 40-48. https://doi.org/10.1002/ajp.20616.

Jasmin, J.-N., \& Devaux, C. (2015). Laterality of leaf cutting in the attine ant Acromyrmex echinatior. Insectes Sociaux, 62, 109114. https://doi.org/10.1007/ s00040-014-0379-x.

Johnson, A. R., \& Cézilly, F. (2007). The greater flamingo. London, U.K.: T \& AD Poyser.

Krakauer, A. H., Blundell, M. A., Scanlan, T. N., Wechsler, M. S., McCloskey, E. A., Yu, J. H., et al. (2016). Successfully mating male sage-grouse show greater laterality in courtship and aggressive interactions. Animal Behaviour, 111, 261-267.

https://doi.org/10.1016/j.anbehav.2015.10.031.

Magat, M., \& Brown, C. (2009). Laterality enhances cognition in Australian parrots. Proceedings of the Royal Society of London B:

Biological Sciences, 276, 4155-4162.

McGreevy, P. D., \& Thomson, P. C. (2006). Differences in motor laterality between breeds of performance horse. Applied

Animal Behaviour Science, 99, 183-190. https://doi.org/10.1016/j.applanim.2005.09.010.

Peluso, A. I., \& Anderson, M. J. (2014). The role of lateralization in feeding behavior and scratching preference in relation to social behavior in captive Caribbean flamingos (Phoenicopterus ruber). Animal Behavior and Cognition, 1, 51-65.

Perrot, C. (2016). Variations individuelles des traits reproducteurs chez le flamant rose: de l'appariement à l'envol des jeunes ( $\mathrm{PhD}$ thesis). Montpellier, France: Montpellier SupAgro.

Perrot, C., Béchet, A., Hanzen, C., Arnaud, A., Pradel, R., \& Cézilly, F. (2016). Sexual display complexity varies non-linearly with age and predicts breeding status in greater flamingos. Scientific Reports, 6, 36242. https://doi.org/10.1038/ srep36242.

Pfannkuche, K. A., Bouma, A., \& Groothuis, T. G. G. (2009). Does testosterone affect lateralization of brain and behaviour? A meta-analysis in humans and other animal species. Philosophical Transactions of the Royal Society of London B: Biological Sciences, 364, 929-942. https://doi.org/10.1098/rstb.2008.0282.

Rend6n, M. A., Garrido, A., Rend6n-Martos, M., Ramírez, J. M., \& Amat, J. A. (2014). Assessing sex-related chick provisioning in greater flamingo Phoenicopterus roseus parents using capture-recapture models. Journal of Animal Ecology, 83, 479-490.

https://doi.org/10.1111/1365-2656.12138. 
Roche, D. G., Binning, S. A., Strong, L. E., Davies, J. N., \& Jennions, M. D. (2013). Increased behavioural lateralization in parasitized coral reef fish. Behavioral Ecology and Sociobiology, 67, 1339-1344. https://doi.org/10.1007/s00265-013- 1562-1. Rogers, L. J. (1980). Lateralisation in the avian brain. Bird Behavior, 2, 1-12. https:// doi.org/10.3727/015613880791573835. Rogers, L. J. (2009). Hand and paw preferences in relation to the lateralized brain. Philosophical Transactions of the Royal Society B: Biological Sciences, 364, 943. https://doi.org/10.1098/rstb.2008.0225.

Rogers, L. J. (2012). The two hemispheres of the avian brain: Their differing roles in perceptual processing and the expression of behavior. Journal of Ornithology, 153, 61-74. https://doi.org/10.1007/s10336-011-0769-z.

Rogers, L. J., \& Andrew, R. (2002). Comparative vertebrate lateralization. Cambridge, U.K.: University Press.

Rogers, L. J., Vallortigara, G., \& Andrew, R. J. (2013). Divided brains: the biology and behaviour of brain asymmetries. Cambridge,

U.K.: Cambridge University Press.

Rogers, L. J., Zucca, P., \& Vallortigara, G. (2004). Advantages of having a lateralized brain. Proceedings of the Royal Society of London B: Biological Sciences, 271(Suppl.), S420-S422.

Romano, M., Parolini, M., Caprioli, M., Spiezio, C., Rubolini, D., \& Saino, N. (2015). Individual and population-level sexdependent lateralization in yellow-legged gull (Larus michahellis) chicks. Behavioural Processes, 115, 109-116. https:// doi.org/10.1016/j.beproc.2015.03.012.

Sarasa, M., Soriguer, R. C., Serrano, E., Granados, J.-E., \& Pérez, J. M. (2014). Postural laterality in Iberian ibex Capra pyrenaica: Effects of age, sex and nursing suggest stress and social information. Laterality: Asymmetries of body, Brain and Cognition, 19, 638654. https://doi.org/10.1080/1357650X.2014.894052.

Sen, P. K. (1968). Estimates of the regression coefficient based on Kendall's Tau. Journal of the American Statistical Association, 63, 1379-1389. https://doi.org/ 10.1080/01621459.1968.10480934.

Str€ockens, F., Güntürkün, O., \& Ocklenburg, S. (2013). Limb preferences in nonhuman vertebrates. Laterality: Asymmetries of body, Brain and Cognition, 18, 536-575. https://doi.org/10.1080/1357650X.2012.723008.

Team, R. C. (2014). R: A language and environment for statistical computing. Vienna, Austria: R Foundation for Statistical Computing.

Teixeira, L. A. (2008). Categories of manual asymmetry and their variation with advancing age. Cortex, 44, 707-716. https://doi.org/10.1016/j.cortex.2006.10.002.

Tinbergen, N. (1952). «Derived » activities; their causation, biological significance, origin, and emancipation during evolution. The Quarterly Review of Biology, 27, 1-32. https://doi.org/10.1086/398642.

Tomkins, L. M., Thomson, P. C., \& McGreevy, P. D. (2010). First-stepping test as a measure of motor laterality in dogs (Canis familiaris). Journal of Veterinary Behavior: Clinical Applications and Research, 5, 247-255.

Tommasi, L. (1999). Footedness in binocular and monocular chicks. Laterality: Asymmetries of Body, Brain and Cognition, 4, 89-95. https://doi.org/10.1080/ 713754325.

Vallortigara, G., \& Regolin, L. (2006). Animal brain lateralization. Cognition, Brain and Behavior (Special issue) X, 187-210.

Vallortigara, G., \& Rogers, L. J. (2005). Survival with an asymmetrical brain: Advantages and disadvantages of cerebral lateralization. The Behavioral and Brain Sciences, 28, 575-633. https://doi.org/10.1017/S0140525X05000105.

Ventolini, N., Ferrero, E. A., Sponza, S., Chiesa, A. D., Zucca, P., \& Vallortigara, G. (2005). Laterality in the wild: Preferential hemifield use during predatory and sexual behaviour in the black-winged stilt. Animal Behaviour, 69, 1077-1084.

Ward, J. P., Milliken, G. W., Dodson, D. L., Stafford, D. K., \& Wallace, M. (1990). Handedness as a function of sex and age in a large population of Lemur. Journal of Comparative Psychology, 104, 167-173. https://doi.org/10.1037/0735-7036.104. 2.167.

Wells, D. L., \& Millsopp, S. (2009). Lateralized behaviour in the domestic cat, Felis silvestris catus. Animal Behaviour, 78, $537-$ 541. https://doi.org/10.1016/ j.anbehav.2009.06.010.

Zentall, T. R. (2001). Imitation in animals: Evidence, function, and mechanisms. Cybernetics \& Systems, 32, 53-96. https://doi.org/10.1080/019697201300001812.

\section{Appendix 1}

We tested the idea that flamingos alternate between their right and left sides during twist-preen sequences, and thus that successive twist-preens are not independent observations. A twist-preen sequence is most often preceded and interspersed by wingsalute, inverted-wing salute or alert postures and generally ends with head flagging, preening or walking. We obtained 63 sequences from 40 individuals for which we recorded the first and second twist-preen. We tested for an effect of the first twistpreen side on the second twist-preen side using general linear mixed model analysis (GLMM). Individual identity was a random factor in this analysis.

The model that assumes a relationship between the first and the second twist-preening side had an Akaike information criterion (AICc) score (slope $=-19.13$, confidence interval, CIslope -29.68 to -8.58 , AICc $=49.01$ ) more than two units lower than the null model (AICc $=88.78)$. We thus concluded that twist-preen sides alternate in a sequence (indicated by the negative slope).

Consequently, in our main analysis we tested for lateralization for the first twist-preen of a sequence only.

Flamingos also seemed to alternate between left and right when performing subsequent preens. Therefore, we performed the above analysis for preen sequences. A preening sequence ends with head flagging or walking. We also retained preen sequences interspersed with alert postures. We analysed the relationship between the first and second preen for 212 sequences recorded from 66 
individuals. Again, the model with an order effect had an AICc score (slope $=-1.34$, CIslope -2.36 to -0.33 , AICc $=277.10$ ) more than two units lower than the null model (AICc $=297.02$ ). Consequently, we tested for lateralization for the first preen only.

\section{Appendix 2}

Lateralization of courtship postures may result from behavioural contagion if the laterality of a focal individual's posture is influenced by the laterality of other animals in its vicinity (Zentall, 2001). To evaluate the hypothesis that lateralization in greater flamingos results from behavioural contagion, we recorded 5-20 min videos of groups of 5-40 individuals forming a display group. To avoid resampling the same group of individuals, we waited 1 week before filming again in the same saltpan.

We analysed events in which several individuals performed a sequence of courtship postures almost synchronously. Such synchronous events were preceded by head flagging and always began with a wing-salute. Because our results indicate that twistpreen is the only lateralized synchronous posture (Fig. 2), we checked behavioural contagion for this behaviour only. We identified the first individual performing a twist-preen in a synchronous event (initiator) and recorded the laterality of its twist-preen (see Appendix 1). Then, we recorded how many individuals displayed left- and right-sided twist-preen within the next $5 \mathrm{~s}$ (followers). For each synchronous event, we calculated the proportion of followers that performed twist-preen to the right as $\mathrm{P}=\mathrm{Right} /$ (Right + Left), where the denominator is the total number of followers.

We tested for the effect of the initiator's twist-preen laterality on the proportion P, using a GLMM controlling for the size of the group and taking the identity of the group into account as a random factor. The scores of the estimators and their confidence intervals were transformed into an odds ratio for a more comprehensive measure of each factor's effect size. To transform the odds ratio, we computed the exponential function of each estimator.

We found no effect of the initiators' twist-preen laterality on the followers' twist-preen laterality (Table A1). This indicates that behavioural contagion was weak and that the laterality of twistpreen was due to the followers' own attributes. All models including the 'behavioural contagion' effect presented AICc scores higher than the null model (Table A1). Moreover, odds ratios' confidence intervals include the value 1 in all models, which suggests that there is no effect of the initiator.

\section{Table A1}

Model selection of the GLMM of the effect of initiators' laterality (I) and group size (G) on the proportion of followers that performed twist-preen on their right side (P) in greater flamingos' group displaying

\begin{tabular}{|c|c|c|c|c|c|}
\hline \multirow[t]{2}{*}{ Model } & \multirow[t]{2}{*}{ Parameter } & \multirow{2}{*}{$\frac{\text { Estimates }}{\text { Odds ratio }}$} & \multirow{2}{*}{$\frac{\mathrm{Cl}}{\mathrm{Cl}_{\text {Odass aso }}}$} & \multirow[t]{2}{*}{$\mathrm{AlCc}$} & \multirow[t]{2}{*}{$\triangle \mathrm{AICc}$} \\
\hline & & & & & \\
\hline \multirow[t]{6}{*}{$P \sim I * G$} & I & 0.305 & 0.495 to 1.104 & 110.589 & 19.642 \\
\hline & & 1.356 & 0.609 to 3.017 & & \\
\hline & G & 0.003 & -0.221 to 0.028 & & \\
\hline & & 1.003 & 0.978 to 1.029 & & \\
\hline & $I \cdot G$ & -0.006 & -0.048 to 0.037 & & \\
\hline & & 0.995 & 0.953 to 1.037 & & \\
\hline \multirow[t]{4}{*}{$\mathrm{P} \sim \mathrm{I}+\mathrm{G}$} & I & 0.206 & -0.078 to 0.491 & 101.567 & 10.620 \\
\hline & & 1.229 & 0.925 to 1.634 & & \\
\hline & G & 0.001 & -0.019 to 0.021 & & \\
\hline & & 1.001 & 0.981 to 1.022 & & \\
\hline \multirow[t]{2}{*}{$P \sim I$} & I & 0.206 & -0.077 to 0.488 & 90.947 & 0 \\
\hline & & 1.224 & 0.926 to 1.629 & & \\
\hline $\mathrm{P} \sim 1$ & & & & 91.269 & 0.322 \\
\hline
\end{tabular}

For each model parameter we provide estimates with theirconfidence intervals ( $\mathrm{Cl}$ ) together with the odds ratio and their confidence intervals ( $\left.\mathrm{Cl}_{\text {odas raio }}\right)$ below in italics. For each model we further provide AICc scores and their difference from the lower AlCc score ( $\triangle \mathrm{AICc}$ ). Synchronous events $=82$; groups $=18$; initiator twistpreen side: right $=37$, left $=45$. 